\title{
Chemo- and Stereodivergent Preparation of Terminal Epoxides and Bromohydrins through One-Pot Biocatalysed Reactions: Access to Enantiopure Five- and Six-Membered $N$-Heterocycles
}

\author{
Fabricio R. Bisogno, ${ }^{\mathrm{a}}$ Aníbal Cuetos, ${ }^{\mathrm{a}}$ Alejandro A. Orden, ${ }^{\mathrm{b}}$ Marcela Kurina-Sanz, \\ Iván Lavandera, and Vicente Gotor ${ }^{\mathrm{a}, *}$ \\ a Departamento de Química Orgánica e Inorgánica, Instituto Universitario de Biotecnología de Asturias, Universidad de \\ Oviedo. C/ Julián Clavería 8, 33006 Oviedo, Spain. \\ Fax: (+) 34985 103448. e-mail: vgs@ fq.uniovi.es. \\ b INTEQUI-CONICET, Área de Química Orgánica, Facultad de Química, Bioquímica y Farmacia, UNSL. Chacabuco y \\ Pedernera, 5700 San Luis, Argentina.
}

Received: ((will be filled in by the editorial staff))

Supporting information for this article is available on the WWW under http://dx.doi.org/10.1002/adsc.200\#\#\#\#\#.

\begin{abstract}
Different enantiopure terminal epoxides or bromohydrins have chemoselectively been synthesised in one-pot starting from the corresponding $\alpha$-bromoketones through alcohol dehydrogenase (ADH)-catalysed processes adding an organic co-solvent and tuning appropriately the medium $\mathrm{pH}$ and the temperature. Thus, at neutral $\mathrm{pH}$ enantiopure bromohydrins were obtained while using basic conditions ( $\mathrm{pH} 9.5-10)$ epoxides were isolated as the main product. Furthermore, by simple selection of the biocatalyst, chemo- and stereodivergent transformations were achieved to obtain, e.g. enantiopure prolinol or piperidin-3-ol.
\end{abstract}

Keywords: one-pot reaction; alcohol dehydrogenases; epoxides; bromohydrins; prolinol; medium engineering

Enantiopure terminal halohydrins and epoxides are valuable functionalities in pharmaceutical industry and natural products synthesis due to their high reactivity allowing the obtaining of a huge variety of compounds. ${ }^{[1]}$ In the last three decades, organo- and transition metal-based approaches have successfully been developed to synthesise these derivatives. ${ }^{[2]}$ Otherwise, environmental friendly enzymatic processes leading to enantioenriched oxiranes and halohydrins have been less developed. ${ }^{[3]}$ Among them, kinetic resolutions using epoxide hydrolases $(\mathrm{EHs})^{[4]}$ and halohydrin dehalogenases (Hhes) ${ }^{[5]}$ have been employed to catalyse the regio- and enantioselective oxirane ring-opening with $\mathrm{H}_{2} \mathrm{O}$ or other nucleophiles, affording the enantioenriched substrate and product with a 50\% maximum yield. Recently, an elegant chemoenzymatic dynamic kinetic resolution procedure leading to aromatic terminal epoxides has been published. ${ }^{[6]}$ Thus, coupling an Ir catalyst which promoted the racemisation of the halohydrins with an Hhe, several $(R)$-oxiranes could be achieved with moderate to high conversions and high enantioselectivities. Another approach has been the P450 monooxygenase-catalysed asymmetric epoxidation of terminal olefins. ${ }^{[7]}$ Halohydrins have been obtained through stereoselective reduction of $\alpha$ haloketones using alcohol dehydrogenases (ADHs). ${ }^{[8]}$ Likewise, terminal epoxides have also been prepared through ADH-based sequential or cascade protocols. ${ }^{[9]}$ In those systems, a terminal $\alpha$ chloroketone was stereoselectively reduced with an $\mathrm{ADH}$ to the corresponding enantiopure chlorohydrin that subsequently cyclisised through Hhe- ${ }^{[9 a-c]}$ or base-catalysed ${ }^{[9 \mathrm{~d}]}$ intramolecular $\mathrm{S}_{\mathrm{N}} 2$ reaction, leading to the epoxides with moderate to high conversions and excellent ees. Similarly, a "designercell"-based two-step procedure was developed to synthesise $(S)$-octene oxide. ${ }^{[10]}$ It is noteworthy that $\mathrm{pH}$ around 13 was set in order to accomplish the oxirane ring-formation, ${ }^{[9 \mathrm{~d}, 10]}$ that can be incompatible with other functionalities.

With this scenario we assumed that employing $\alpha$ bromoketones ${ }^{[10,11]}$ instead of $\alpha$-chloroketones, we could synthesise enantioenriched terminal oxiranes or bromohydrins in one-pot by simple use of a catalyst (an ADH) and a catalytic amount of cofactor employing 2-propanol to recycle it ('substratecoupled' approach) ${ }^{[12]}$ at suitable $\mathrm{pH}$ conditions for the enzyme (Scheme 1). Furthermore, an application to obtain $N$-heterocyclic compounds is also shown.

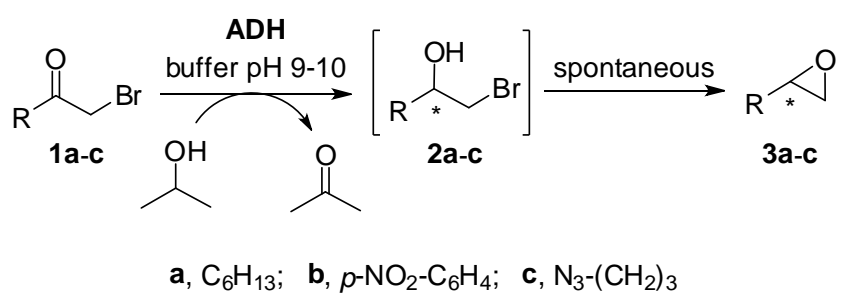

Scheme 1. One-pot synthesis of enantiopure terminal epoxides. 
For this purpose, we chose 1-bromooctan-2-one (1a) $^{[10]}$ as model substrate. Using Lactobacillus brevis $\mathrm{ADH}(\mathrm{LBADH})^{[13]}$ as catalyst at $\mathrm{pH} 7.5$, only $10 \%$ of enantiopure $(S)$-epoxide 3a was obtained after $24 \mathrm{~h}$, so Tris. $\mathrm{SO}_{4}$ buffers ranging from $\mathrm{pH} 7.5$ until 10 were tested (see Supporting Information). Obviously, the best conversion into 3a (47\%) was found with the highest $\mathrm{pH}$, although we observed that other minor compounds were also formed. In this sense, blank experiments demonstrated that the corresponding hydroxyketone (4a) was formed by $\mathrm{S}_{\mathrm{N}} 2$ reaction over substrate 1a, and diol 5a appeared due to the ADHcatalysed reduction of $\mathbf{4 a}{ }^{[14]}$ To circumvent this fact it was envisaged that an amount of a waterimmiscible solvent could result in a reservoir for both substrate and products (Scheme 2).

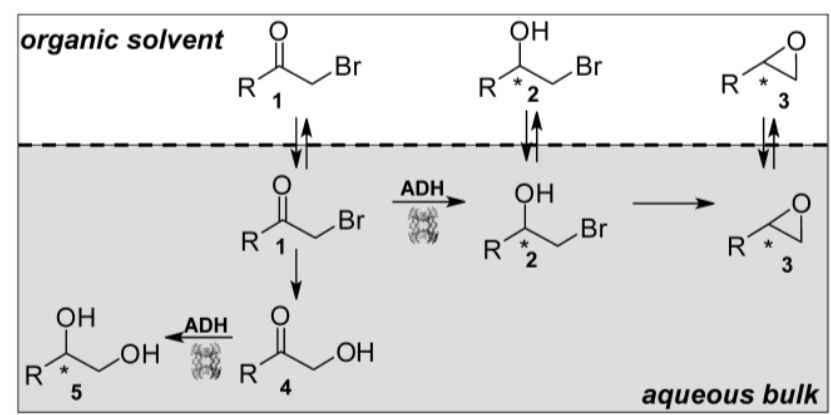

Scheme 2. (Bio)transformations in a biphasic aqueousorganic system.

Consequently, several organic solvents such as $n$ pentane, $n$-hexane, cyclohexane, $n$-heptane and $n$ decane were assayed at $5 \% \mathrm{v} \mathrm{v}^{-1}$ leading to almost exclusive formation of $\mathbf{2 a}$ and $\mathbf{3 a}$ after $24 \mathrm{~h}$, although the cyclisation rate diminished (see Supporting Information). Since no relevant difference was noticed among them, $n$-hexane was selected as the organic co-solvent. The addition of the organic phase was advantageous to suppress the undesired $\mathrm{S}_{\mathrm{N}} 2$ reaction over $\alpha$-bromoketone 1a, but also delayed the enzymatic reduction to obtain $\mathbf{2 a}$ and the ring-closure to achieve 3a, so a compromise had to be found. To optimise the reaction outcome, a study of the $n$ hexane concentration $\left(3-20 \% \mathrm{v} \mathrm{v}^{-1}\right)$ was carried out (Figure 1). As expected, it was observed that at higher percentages of the organic co-solvent, less quantity of by-products was formed although going in hand with a lower cyclisation rate. Hence, $5 \% \mathrm{v} \mathrm{v}^{-1}$ of $n$-hexane was the compromise concentration.

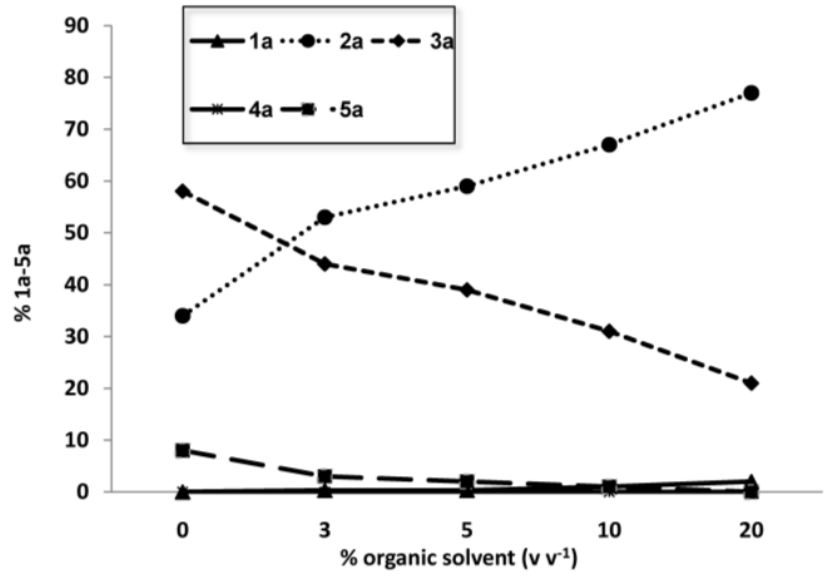

Figure 1. Co-solvent concentration effect on the products ratio in the biotransformation of 1a into 3a after $24 \mathrm{~h}$.

In these conditions, we observed a clean reaction with complete consumption of $\mathbf{1 a}$ and a promising $42 \%$ of 3a after $24 \mathrm{~h}$. In an attempt to maximise the oxirane formation, it was designed a thermally controlled experiment consisting of the enzymatic bioreduction at $30^{\circ} \mathrm{C}$ followed by the intramolecular $\mathrm{S}_{\mathrm{N}} 2$ transformation at $45^{\circ} \mathrm{C}$ by simply setting a temperature program. Thus, the reaction progress at $30^{\circ} \mathrm{C}$ was studied (Figure 2) to check the time needed to consume $\alpha$-bromoketone 1a. As can be noted after $12 \mathrm{~h}$ this compound disappeared, only forming traces $(<2 \%)$ of diol 5a.

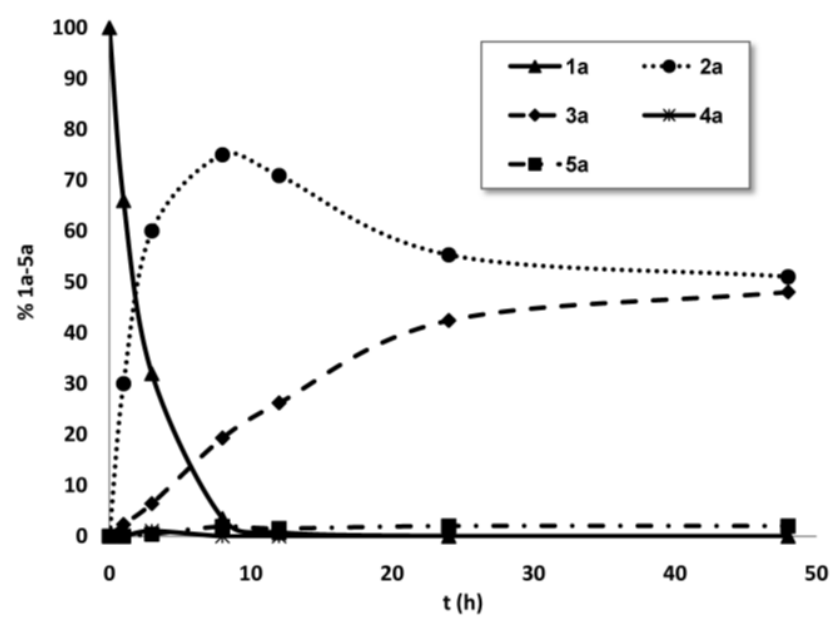

Figure 2. Time-course of the enzymatic transformation of 1a into 3a catalysed by $\mathrm{LBADH}$ in Tris. $\mathrm{SO}_{4}$ buffer $\mathrm{pH} 10$ at $30^{\circ} \mathrm{C}$ in the presence of $5 \% \mathrm{v} \mathrm{v}^{-1}$ of $n$-hexane. 
Table 1. Biocatalysed synthesis of enantiopure epoxides and bromohydrins in a biphasic system. ${ }^{\text {[a] }}$

\begin{tabular}{|c|c|c|c|c|c|c|c|c|}
\hline entry & $\mathbf{1}$ & conv. ${ }^{[b]}$ & $e e^{[\mathrm{c}, \mathrm{d}]}$ & $2^{[b]}$ & $\mathbf{3}^{[\mathrm{b}]}$ & $\mathrm{T}$ program & $\mathrm{pH}$ & ADH \\
\hline 1 & 1a & 98 & $>99(S)$ & 56 & 42 & $24 \mathrm{~h} 30^{\circ} \mathrm{C}$ & 10 & LB \\
\hline 2 & 1a & 99 & $>99(S)$ & $<1$ & 98 & $13 \mathrm{~h} 30^{\circ} \mathrm{C} / 18 \mathrm{~h} 45^{\circ} \mathrm{C}$ & 10 & LB \\
\hline 3 & 1a & $>99$ & $>99(R)$ & 9 & 90 & $13 \mathrm{~h} 30^{\circ} \mathrm{C} / 18 \mathrm{~h} 45^{\circ} \mathrm{C}$ & 10 & $\mathrm{~T}$ \\
\hline $4^{[\mathrm{e}]}$ & 1b & $>99$ & $>99(S)$ & $<1$ & 84 & $13 \mathrm{~h} 30^{\circ} \mathrm{C} / 18 \mathrm{~h} 45^{\circ} \mathrm{C}$ & 9.5 & LB \\
\hline 5 & $1 b$ & 99 & $>99(R)$ & $<1$ & 98 & $13 \mathrm{~h} 30^{\circ} \mathrm{C} / 18 \mathrm{~h} 45^{\circ} \mathrm{C}$ & 9.5 & $\mathrm{~T}$ \\
\hline 6 & $1 c$ & 87 & $>99(S)$ & 4 & 83 & $36 \mathrm{~h} 30^{\circ} \mathrm{C}$ & 9.5 & LB \\
\hline 7 & 1a & $>99$ & $>99(S)$ & 99 & $<1$ & $18 \mathrm{~h} 30^{\circ} \mathrm{C}$ & 7.5 & LB \\
\hline 8 & $\mathbf{1 a}$ & 99 & $>99(R)$ & 98 & $<1$ & $18 \mathrm{~h} 30^{\circ} \mathrm{C}$ & 7.5 & $\mathrm{~T}$ \\
\hline 9 & 1b & $>99$ & $>99(S)$ & 85 & 15 & $18 \mathrm{~h} 30^{\circ} \mathrm{C}$ & 7 & LB \\
\hline 10 & $1 b$ & $>99$ & $>99(R)$ & 93 & 7 & $18 \mathrm{~h} 30^{\circ} \mathrm{C}$ & 7 & $\mathrm{~T}$ \\
\hline 11 & 1c & $>99$ & $>99(S)$ & 99 & $<1$ & $18 \mathrm{~h} 30^{\circ} \mathrm{C}$ & 7.5 & LB \\
\hline
\end{tabular}

[a] For reaction conditions, see Supporting Information. [b] Measured by GC. [c] Measured by chiral GC or HPLC. [d] Switch in Cahn-Ingold-Prelog (CIP) priority. [e] $15 \%$ of by-products were formed.

Thus, employing a program that comprised $13 \mathrm{~h}$ at $30^{\circ} \mathrm{C}$ followed by $18 \mathrm{~h}$ at $45^{\circ} \mathrm{C}$ excellent epoxide conversion was achieved (Table 1). This one-pot sequential process enabled the formation of enantiopure $(S)$ - or $(R)$-3a with excellent yields by simple selection of the biocatalyst, using either LBADH (entry 2) or ADH from Thermoanaerobacter $\mathrm{sp}^{[15]}$ (ADH-T, entry 3), respectively.

Since this one-pot two-step procedure rendered excellent results for this aliphatic substrate, we decided to apply this methodology with an aromatic ketone such as $\alpha$-bromo- $p$-nitroacetophenone (1b), obtaining with ADH-T a complete conversion of enantiopure (R)-p-nitrostyrene oxide (3b), and a conversion of $84 \%$ and $>99 \%$ ee of $(S)-3 \mathbf{b}$ using LBADH (Table 1, entries 4-5). For this derivative a slightly lower $\mathrm{pH}$ (9.5) was chosen, since at $\mathrm{pH} 10$ higher amounts of by-products were detected.

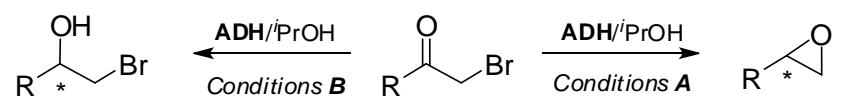

Scheme 3. Chemo- and stereodivergent preparation of $\beta$ bromo alcohols and epoxides starting from $\alpha$ bromoketones. Conditions A: ADH, 2-propanol, Tris. $\mathrm{SO}_{4}$ buffer $\mathrm{pH} 9.5-10, n$-hexane, $30^{\circ} \mathrm{C}$ plus a $45^{\circ} \mathrm{C}$ period. Conditions $B: \mathrm{ADH}, 2$-propanol, Tris. $\mathrm{SO}_{4}$ buffer $\mathrm{pH}$ 7-7.5, $n$-hexane, $30^{\circ} \mathrm{C}$.

Furthermore, taking benefit from the versatility of the medium parameters, we can use this methodology to synthesise selectively the corresponding bromohydrins with high conversions and optical purities. Since it was observed in previous experiments that lower $\mathrm{pHs}$ and the presence of an organic co-solvent diminished the cyclisation rate, we exploited this to obtain the bromohydrins 2a-b (Scheme 3). Therefore, experiments were carried out at lower $\mathrm{pH}(7-7.5)$ and $30^{\circ} \mathrm{C}$ with $5 \% \mathrm{v} \mathrm{v}^{-1} n$-hexane (entries 7-10). Thus, enantiopure derivatives $(S)$ - and $(R)-\mathbf{2 a}-\mathbf{b}$ were preferentially obtained using both ADHs. To show the feasibility of these protocols, enantiopure $(S)$-alcohol 2a and $(S)$-epoxide 3a were prepared on a higher scale starting from $120 \mathrm{mg}$ of the $\alpha$-bromoketone 1a with excellent isolated yields (see SI).

At this point we were interested in applying this methodology to obtain other valuable derivatives. Enantiopure prolinol and related structures are important chiral auxiliaries in hydrogen transfer protocols as well as asymmetric epoxidations and catalysts in aldol condensations, Michael type additions and other C-C bond-forming reactions. ${ }^{[16]}$ Moreover, chiral $\mathrm{N}$-containing heterocycles are quite common in natural alkaloids and derivatives, ${ }^{[17]}$ and therefore, it becomes interesting to develop new strategies for their preparation. ${ }^{\text {18] }}$ Epoxides and halohydrins are considered as similar chemical functionalities but they can offer different features that can be exploited chemoselectively. To show this, 5-azido-1-bromopentan-2-one (1c) was reduced with $\mathrm{LBADH}$, affording enantiopure bromohydrin $2 \mathrm{c}$ or epoxide $3 \mathbf{c}$ in high conversions (Table 1, entries 6 and 10). These reactions were performed at $100 \mathrm{mg}$ scale obtaining similar results. It was envisaged that these derivatives could be reduced to the highly reactive (non isolated) amino compounds that would spontaneously cyclisise ${ }^{[19]}$ affording prolinol or piperidin-3-ol through $\mathrm{S}_{\mathrm{N}} 2$ reactions (Scheme 4). We firstly decided to optimise the reduction step using some reducing reagents such as $\mathrm{NaBH}_{4}$ and $\mathrm{H}_{2}-\mathrm{Pd} / \mathrm{C}$ but in case of $3 \mathbf{c}$ the oxirane moiety was unstable. However, by means of the Staudinger reaction using $\mathrm{PPh}_{3}$ and $\mathrm{H}_{2} \mathrm{O},{ }^{[20]}$ the desired reduction was successfully accomplished. In case of the amino epoxide, it spontaneously evolved into prolinol with inversion of the configuration following a 5-Exo-Tet process, instead of piperidin-3-ol through an impeded 6-Endo-Tet route according to Baldwin' rules (Scheme 4, left). ${ }^{[21]}$ On the other hand, bromohydrin 2c afforded the piperidine derivative as the sole product through a favoured 6-Exo-Tet pathway (Scheme 4, right). ${ }^{[21]}$ Once optimised all individual steps, enantiopure $(R)$-prolinol and $(S)$-piperidin-3-ol were obtained as the corresponding $N$-Boc and N$\mathrm{CBz}$ derivatives, respectively, through this three-step 
procedure. These transformations could be performed following a one-pot protocol, although better yields were achieved when the Staudinger reduction was performed after isolation of $(S)$-2c or $(S)$-3c. This procedure shows an elegant chemodivergent strategy that can be applied to the synthesis of different heterocyclic-bearing scaffolds with good yields and optical purities.

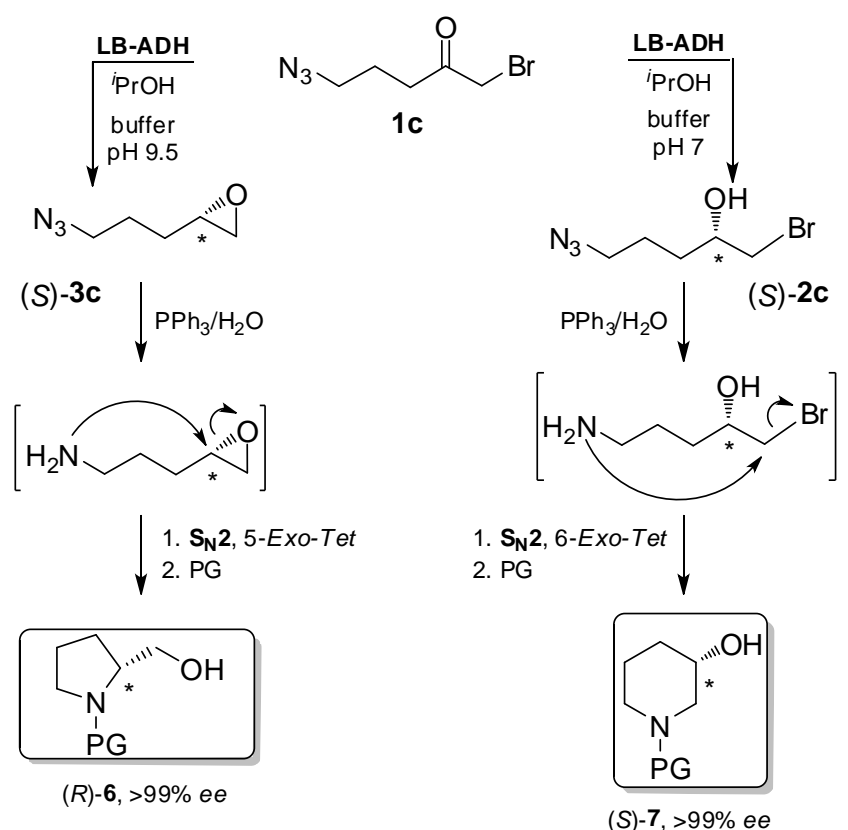

Scheme 4. Biocatalysed chemodivergent synthesis of enantiopure $N$-protected $(R)$-prolinol and $(S)$-piperidin-3-ol.

In conclusion, we have developed an efficient onepot chemo- and stereodivergent enzymatic process applied to the preparation of both enantiopure terminal epoxides or $\beta$-bromo alcohols starting from the corresponding $\alpha$-bromoketones just tuning the reaction conditions. This is a nice example of the application of the medium engineering ${ }^{[22]}$ to an enzymatic process to perform transformations using mild reaction conditions to achieve the selective formation of several derivatives in high yields choosing the stereochemistry by employing the appropriate biocatalyst. Furthermore, applying this chemodivergent methodology very interesting compounds such as prolinol or piperidin-3-ol could readily be synthesised. Other heterocycles may be prepared by selecting the suitable precursor. A more comprehensive study of the presented system is currently under way in our laboratories.

\section{Experimental Section}

Synthesis of $(\boldsymbol{S})-\boldsymbol{N}$-CBz-piperidin-3-ol $(\boldsymbol{S})-7 .^{[23]} 100 \mathrm{mg}$ of 1c were incubated in Tris.SO $\mathrm{SO}_{4}$ buffer $50 \mathrm{mM} \mathrm{pH} 7.5(20$ $\mathrm{mL})$ containing NADPH $(1 \mathrm{mM})$ and $\operatorname{MgBr}_{2}(1 \mathrm{mM})$ in the presence of 2-propanol $\left(5 \% \mathrm{v} \mathrm{v}^{-1}\right)$ and $n$-hexane $\left(5 \% \mathrm{v} \mathrm{v}^{-1}\right)$ with $\mathrm{LBADH}(10 \mathrm{U})$ for $18 \mathrm{~h}$ at $30^{\circ} \mathrm{C}$. The reaction was extracted with $\mathrm{Et}_{2} \mathrm{O}(3 \times 5 \mathrm{~mL})$ and the organic layers were dried and evaporated. The crude was dissolved in THF (4 $\mathrm{mL}$ ), and $\mathrm{PPh}_{3}$ (2 equiv.) and $\mathrm{H}_{2} \mathrm{O}$ (2 equiv.) were added. The reaction was stirred for $24 \mathrm{~h}$ at room temperature. Then, the solvent was evaporated and the crude was extracted with $\mathrm{CH}_{2} \mathrm{Cl}_{2} / \mathrm{HCl} 3 \mathrm{~N}$. The aqueous phase obtained $(10 \mathrm{~mL})$ was set to $\mathrm{pH} 8-9$ with a satd. solution of $\mathrm{Na}_{2} \mathrm{CO}_{3} 3 \mathrm{~N}$ and then $\mathrm{CH}_{2} \mathrm{Cl}_{2}(5 \mathrm{~mL})$ and $\mathrm{CBz}-\mathrm{Cl}(1.2$ equiv.) were added and the biphasic system was stirred for $12 \mathrm{~h}$. The crude was extracted with $\mathrm{CH}_{2} \mathrm{Cl}_{2}$ and was subjected to flash chromatography over silica gel eluted with EtOAc/ $\mathrm{CH}_{2} \mathrm{Cl}_{2}$ (from $1: 1$ to 2:1) affording enantiopure $(S)-7$ (40\%). ${ }^{1} \mathrm{H}-\mathrm{NMR}\left(300 \mathrm{MHz}, \mathrm{CDCl}_{3}\right)$ : $\delta 1.40-1.50\left(\mathrm{~m}, 2 \mathrm{H}, \mathrm{H}_{4}\right), 1.65-1.80\left(\mathrm{~m}, 2 \mathrm{H}, \mathrm{H}_{5}\right), 1.91(\mathrm{br} s$, $\left.1 \mathrm{H}, \mathrm{H}_{\mathrm{OH}}\right), 3.01-3.13\left(m, 2 \mathrm{H}, \mathrm{H}_{6}\right) 3.49-3.74\left(m, 3 \mathrm{H}, \mathrm{H}_{2}+\mathrm{H}_{3}\right)$, $5.03\left(s, 2 \mathrm{H}, \mathrm{H}_{\mathrm{b}}\right)$ and $7.24\left(m, 5 \mathrm{H}, \mathrm{H}_{\mathrm{ar}}\right) ;{ }^{13} \mathrm{C}-\mathrm{NMR}(75 \mathrm{MHz}$, $\left.\mathrm{CDCl}_{3}\right): \delta 22.2\left(\mathrm{CH}_{2}, \mathrm{C}_{4}\right), 32.2\left(\mathrm{CH}_{2}, \mathrm{C}_{5}\right), 44.0\left(\mathrm{CH}_{2}, \mathrm{C}_{6}\right)$ $50.6\left(\mathrm{CH}_{2}, \mathrm{C}_{2}\right), 65.8\left(\mathrm{CH}, \mathrm{C}_{3}\right), 67.9\left(\mathrm{CH}_{2}, \mathrm{C}_{\mathrm{b}}\right), 127.7(\mathrm{C}$ $\left.\mathrm{C}_{\mathrm{i}}\right), 127.9\left(2 \mathrm{CH}, \mathrm{C}_{\mathrm{m}}\right), 128.4\left(2 \mathrm{CH}, \mathrm{C}_{\mathrm{o}}\right), 136.6\left(\mathrm{CH}, \mathrm{C}_{\mathrm{p}}\right)$ and $155.6(\mathrm{C}, \mathrm{C}=\mathrm{O})$.

\section{Acknowledgements}

F.R.B. is supported by the Programme AlBan, the European Union Program of High Level Scholarships for Latin America (scholarship No. E07D402519AR). A.C. thanks Universidad de Oviedo for a pre-doctoral fellowship. A.A.O. is a postdoctoral CONICET fellow. M.K.-S. is member of the Research Career of CONICET. I.L. thanks the Spanish Ministerio de Ciencia e Innovación (MICINN) for personal funding (Ramón y Cajal Program). Financial support from MICINN (Project CTO200761126) and the Spanish Ministerio de Asuntos Exteriores y de Cooperación (Programa de Cooperación Interuniversitaria, PCI Iberoamérica MAEC-AECID, Project A/8856/07) is gratefully acknowledged. Dedicated to Prof. Oscar S. Giordano on the occasion of his retirement.

\section{References}

[1] a) M. Breuer, K. Ditrich, T. Habicher, B. Hauer, M. Kesseler, R. Stürmer, T. Zelinski, Angew. Chem. 2004 116, 806-843; Angew. Chem. Int. Ed. 2004, 43, 788824; b) A. Kleemann, J. Engels, B. Kutscher, D. Reichert, Pharmaceutical Substances: Syntheses, Patents, Applications, 4th ed., Thieme-Verlag, Stuttgart, 2001; c) A. Archelas, R. Furstoss, Annu. Rev. Microbiol. 1997, 51, 491-525.

[2] a) I. W. C. E. Arends, Angew. Chem. 2006, 118, 63986400; Angew. Chem. Int. Ed. 2006, 45, 6250-6252; b) Y. Shi, Acc. Chem. Res. 2004, 37, 488-496; c) M. Tokunaga, J. F. Larrow, F. Kakiuchi, E. N. Jacobsen, Science 1997, 277, 936-938; d) P. Besse, H. Veschambre, Tetrahedron 1994, 50, 8885-8927; e) K. B. Sharpless, CHEMTECH 1985, 15, 692-700.

[3] a) Modern Biocatalysis, (Eds: W.-D. Fessner, T. Anthonsen), Wiley-VCH, Weinheim, 2009; b) Asymmetric Organic Synthesis with Enzymes, (Eds: V. Gotor, I. Alfonso, E. García-Urdiales), Wiley-VCH, Weinheim, 2008; c) K. Faber, Biotransformations in Organic Chemistry, 5th ed., Springer, Berlin, 2004; d) E. J. de Vries, D. B. Janssen, Curr. Opin. Biotechnol. 2003, 14, 414-420.

[4] R. Chênevert, P. Morin, N. Pelchat, in Asymmetric Organic Synthesis with Enzymes, (Eds: V. Gotor, I. Alfonso, E. García-Urdiales), Wiley-VCH, Weinheim, 2008, pp. 133-169. 
[5] D. B. Janssen, M. Majerić Elenkov, G. Hasnaoui, B. Hauer, J. H. Lutje Spelberg, Biochem. Soc. Trans. 2006, 34, 291-295.

[6] R. M. Haak, F. Berthiol, T. Jerphagnon, A. J. A. Gayet, C. Tarabiono, C. P. Postema, V. Ritleng, M. Pfeffer, D. B. Janssen, A. J. Minnaard, B. L. Feringa, J. G. de Vries, J. Am. Chem. Soc. 2008, 130, 13508-13509.

[7] T. Kubo, M. W. Peters, P. Meinhold, F. H. Arnold, Chem. Eur. J. 2006, 12, 1216-1220.

[8] Recent examples with isolated or over-expressed ADHs: a) E. Alanvert, C. Doherty, T. S. Moody, N. Nesbit, A. S. Rowan, S. J. C. Taylor, F. Vaughan, T. Vaughan, J. Wiffen, I. Wilson, Tetrahedron: Asymmetry 2009, 20, 2462-2466; b) F. R. Bisogno, I. Lavandera, W. Kroutil, V. Gotor, J. Org. Chem. 2009, 74, 1730-1732; c) D. Zhu, B. A. Hyatt, L. Hua, J. Mol. Catal. B: Enzym. 2009, 56, 272-276.

[9] a) J. H. Schrittwieser, I. Lavandera, B. Seisser, B. Mautner, W. Kroutil, Eur. J. Org. Chem. 2009, 22932298; b) J. H. Schrittwieser, I. Lavandera, B. Seisser, B. Mautner, J. H. Lutje Spelberg, W. Kroutil, Tetrahedron: Asymmetry 2009, 20, 483-488; c) B. Seisser, I. Lavandera, K. Faber, J. H. Lutje Spelberg, W. Kroutil, Adv. Synth. Catal. 2007, 349, 1399-1404; d) T. M. Poessl, B. Kosjek, U. Ellmer, C. C. Gruber, K. Edegger, K. Faber, P. Hildebrandt, U. T. Bornscheuer, W. Kroutil, Adv. Synth. Catal. 2005, 347, 1827-1834.

[10] A. Berkessel, C. Rollmann, F. Chamouleau, S. Labs, O. May, H. Gröger, Adv. Synth. Catal. 2007, 349, 2697-2704.

[11] These substrates can easily be obtained starting from the corresponding ketones or alkenes. See, for instance: a) R. D. Patil, G. Joshi, S. Adimurthy, B. C. Ranu, Tetrahedron Lett. 2009, 50, 2529-2532; b) I. Pravst, M. Zupana, S. Stavber, Green Chem. 2006, 8, 1001-1005; c) H. Y. Choi, D. Y. Chi, Org. Lett. 2003, 5, 411-414.

[12] For recent examples, see: a) J. Liang, J. Lalonde, B. Borup, V. Mitchell, E. Mundorff, N. Trinh, D. A. Kochrekar, R. N. Cherat, G. G. Pai, Org. Process Res. Devel. 2010, 14, 193-198; b) M. Kurina-Sanz, F. R. Bisogno, I. Lavandera, A. A. Orden, V. Gotor, $A d v$. Synth. Catal. 2009, 351, 1842-1848; c) M. J. Sorgedrager, F. van Rantwijk, G. W. Huisman, R. A. Sheldon, Adv. Synth. Catal. 2008, 350, 2322-2328; d) I.
Lavandera, A. Kern, M. Schaffenberger, J. Gross, A. Glieder, S. de Wildeman, W. Kroutil, ChemSusChem 2008, 1, 431-436; e) M. M. Musa, K. I. ZiegelmannFjeld, C. Vieille, J. G. Zeikus, R. S. Phillips, Angew. Chem. 2007, 119, 3151-3154; Angew. Chem. Int. Ed. 2007, 46, 3091-3094.

[13] M. Wolberg, W. Hummel, C. Wandrey, M. Müller, Angew. Chem. 2000, 112, 4476-4478; Angew. Chem. Int. Ed. 2000, 39, 4306-4308.

[14] Blank experiments incubating separately compounds 1a, 2a, and 3a in Tris. $\mathrm{SO}_{4}$ buffer $\mathrm{pH} 10$ showed that only $\alpha$-bromoketone was unstable, while derivatives $\mathbf{2 a}$ and 3a did not decompose (see Supporting Information).

[15] Z. Findrik, D. Vasić-Racki, S. Lütz, T. Daussmann, C. Wandrey, Biotechnol. Lett. 2005, 27, 1087-1095.

[16] a) A. Lattanzi, Chem. Commun. 2009, 1452-1463; b) A. Mielgo, C. Palomo, Chem. Asian J. 2008, 3, 922948; c) C. Palomo, A. Mielgo, Angew. Chem. 2006, 118, 8042-8046; Angew. Chem. Int. Ed. 2000, 45, 7876-7880.

[17] a) M. Brasholz, H-U. Reissig, R. Zimmer, Acc. Chem. Res. 2009, 42, 45-56; b) S. D. Koulocheri, E. N. Pitsinos, S. A. Haroutounian, Curr. Org. Chem. 2008, 12, 1454-1467; c) C. J. Moody, Chem. Commun. 2004, 1341-1351. d) D. Enders, C. Thiebes, Pure Appl. Chem. 2001, 73, 573-578.

[18] V. Köler, K. R. Bailey, A. Znabet, J. Raftery, M. Helliwell, N. J. Turner, Angew. Chem. 2010, 122, 2228-2230; Angew. Chem. Int. Ed. 2010, 49, 21822184.

[19] S. F. Mayer, W. Kroutil, K. Faber, Chem. Soc. Rev. 2001, 30, 332-339.

[20] H. Staudinger, J. Meyer, Helv. Chim. Acta 1919, 2, 635-646.

[21] J.E. Baldwin J. Chem. .Soc., Chem. Commun. 1976, 734-736.

[22] G. Carrea, S. Riva, Angew. Chem. 2000, 112, $2312-$ 2341; Angew. Chem. Int. Ed. 2000, 39, 2226-2254.

[23] R. K. Olsen, K. L. Bhat, R. B. Wardle, W. J. Hennen, G. D. Kini, J. Org. Chem. 1985, 50, 896-899. 


\section{COMMUNICATION}

Chemo- and Stereodivergent Preparation of Terminal Epoxides and Bromohydrins through One-Pot Biocatalysed Reactions: Access to Enantiopure Five- and Six-Membered $N$ Heterocycles

Adv. Synth. Catal. Year, Volume, Page - Page

Fabricio R. Bisogno, Aníbal Cuetos, Alejandro A. Orden, Marcela Kurina-Sanz, Iván Lavandera, and Vicente Gotor*

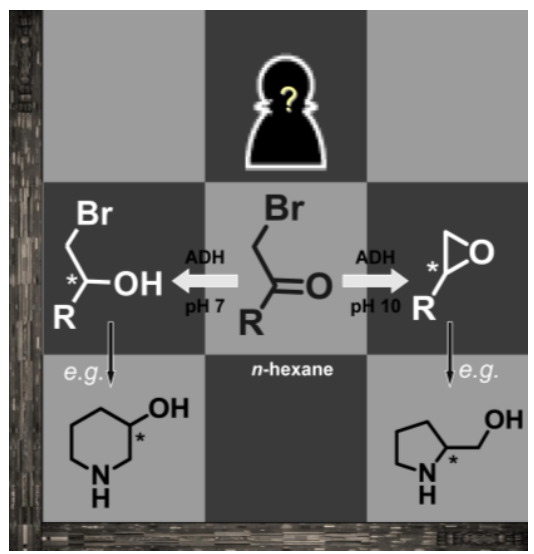

